\title{
Urea Stripper Tube Leakage
}

\author{
Prem Baboo \\ Sr. Manager (Prod) \\ National Fertilizers Ltd. India \\ Sr. advisor for www.ureaknowhow.com
}

\begin{abstract}
This article entails the chronic problem of Fertilizer Industry regarding leakage in Urea Stripper. A critical leak incident that occurred in one of the most critical piece of equipment (stripper) in Urea plant resulted to emergency shutdown and losses in production and how the situation can be analyzed to prevent re- occurrence of similar incidents in chemical Industry. On dated 19/01/2018 at $05.30 \mathrm{hrs}$. Suddenly 31 stream urea stripper got heavy leakage and carbamate came out through pressure safety valve in shell side of heat exchanger (stripper). A rupture in old plug of the tube of a high pressure caused leakage of high pressure urea solution and ammonium carbamate to the atmosphere which results to emergency shutdown and losses in production for three days. Leakage was so big that Shell became pressurized up to PSV setting value i.e. 26.0 bar. Immediately shut down was taken to control the situation. The intent of this article is to highlight the issues faced in identification of Urea Stripper leakage during plant operation and rectification of the problems.
\end{abstract}

\section{INTRODUCTION}

The National Fertilizers Ltd. Vijaipur have two ammonia plant M/S. Haldor Topsoe Technology, Denmark capacity $1750 \& 1864$ TPD for Line-I \& line-II respectively and four urea plant of M/S. Saipem ammonia stripping process, Italy. The Line-I plant installed in 1988 and that of line -II in 1997. Urea-II plant was commissioned in $1^{\text {st }}$ quarter of year 1997 and commercial production was declared on 31.03.1997. The capacity of Urea-I urea -II is 3030 \& 3231 TPD respectively. The raw material used includes natural gas, water and power. Three Numbers Captive power plant of capacity $17 \times 3 \mathrm{MW}$ are used in this complex. The two no of bimetallic strippers were supplied by M/S FBM, Hudson, Italy which are in use since the inception of the plant. The maintenance history of these stripper shows that leakages occurred at different point of time which forced unexpected plant shutdowns and interruption of urea production.

\section{Detail of Stripper}

Urea Stripper is considered as the backbone of Urea Plant performance and efficiency. Its performance determines production and profitability of end product which is Urea Fertilizer.

Reaction products leaving the reactor are sent into bimetallic stripper tubes sides for carbamate decomposition. The medium pressure steam (23 bar) is used for this purpose. The stripper is the high pressure vessel of H.P loop. Operating at 147 bar in tube side pressure and that of shell side is 24 bar. The top temperature of stripper is $190{ }^{\circ} \mathrm{C}$ and that of bottom is $205^{\circ} \mathrm{C}$.at this temperature approximate 80 $\%$ of carbamate presents in solution is decomposed and rest are decomposed in MP \& LP section. The water is separated in pre-concentrator and two stages of vacuum evaporation sections. The decomposition reaction is a reverse reaction of urea formation.

\section{$\mathrm{NH}_{4} \mathrm{COONH}_{2}=\mathrm{NH}_{3}+\mathrm{CO}_{2}-\mathrm{HEAT}$}

As can be inferred from the equation, decomposition is promoted by reducing pressure and /or adding heat. In M/S. Saipem process decomposition is carried out in three steps. Decomposition is promoted by heating and stripping $\mathrm{CO}_{2}$ by vaporized excess ammonia, according to Henry's Law of partial pressure under the same pressure level as urea reactor. The plant commissioned in 1997 till date stripper is running. During pre-commissioning 55 no of tubes plugged in presence of Saipem representative. Tubes were plugged as Zirconium lining of these tubes was found damaged. In present shut down one damaged old plug replaced with new one and others eight numbers minor leakages also attended by applying plug and welding done. Leakage. Stripper used is falling film type heat exchanger decomposed and vaporized gases and liquid effluent are therefore in counter current contact and $\mathrm{CO}_{2}$ concentration in liquid is gradually reduced from top to bottom of the stripper tubes. Besides the above, general corrosion has been observed on the bottom tube sheet, tube to tube sheet welding and bottom part of tubes $(20 \mathrm{~mm})$. Stripper has rendered service for around 21 years. Two types of stripping process are there; Viz: $\mathrm{CO}_{2}$ stripping and $\mathrm{NH}_{3}$ stripping. Both process work according to shift in partial pressure. This process is the most modern and energy efficient and therefore, widely used now a day. Decomposition at high pressure requires higher temperature, which means that much biuret has formed and the liquid becomes corrosive, but in the M/S. Saipem process the excess of ammonia and the use of Zirconium in the stripper permits minimizing these problems. The off gases generated in stripper are condensed in the high 


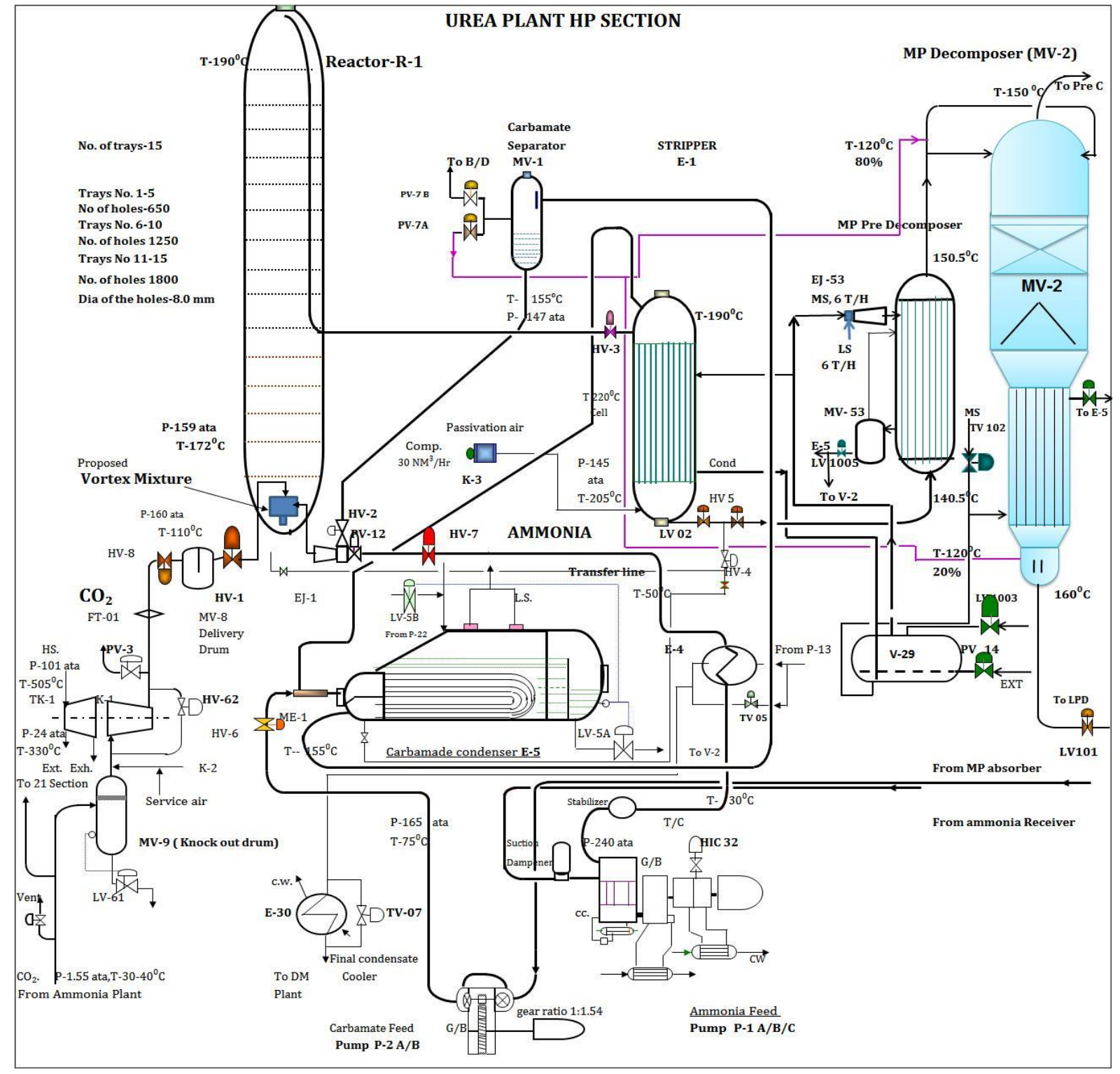

Fig-1

Pressure carbamate condenser where low pressure steam is generated. The $\mathrm{NH}_{3}$ to $\mathrm{CO}_{2}$ mole ratio of $3.5: 1$ is used and the reactor is operated at a pressure by which the carbamate solution is pumped to the reactor by ejector but not using Carbamate pumps.

For passivation of bottom parts of stripper, a passivation compressor also installed to give air in bottom dome. About $42 \mathrm{Nm}^{3} / \mathrm{hr}$ air is feed to stripper bottom. $\mathrm{CO}_{2}$ fed to Reactor normally contains a small percentage of $\mathrm{H}_{2}, \mathrm{CH}_{4} \& \mathrm{CO}$ in addition to inerts like $\mathrm{N}_{2} \&$ Ar. The passivation air also given to $\mathrm{CO}_{2}$ in $1^{\text {st }}$ stage suction of $\mathrm{CO}_{2}$ compressor. We maintained 0.35 to $0.4 \% \quad \mathrm{O}_{2}$ in $3^{\text {rd }}$ suction of $\mathrm{CO}_{2}$ compressor. Together with $\mathrm{O}_{2}$ contained in passivation air could give rise to explosiveness problem when sent to CPP for HRU fuel to avoid explosive mixture natural gas also fed to MP condenser so that explosive mixture in inerts gas could not be made. Passivation air presents a major issue for urea process. Designed to prevent the corrosion of stainless steel, passivation air constantly coats the inner surface of stripper tubes with an oxygenated process solution. 


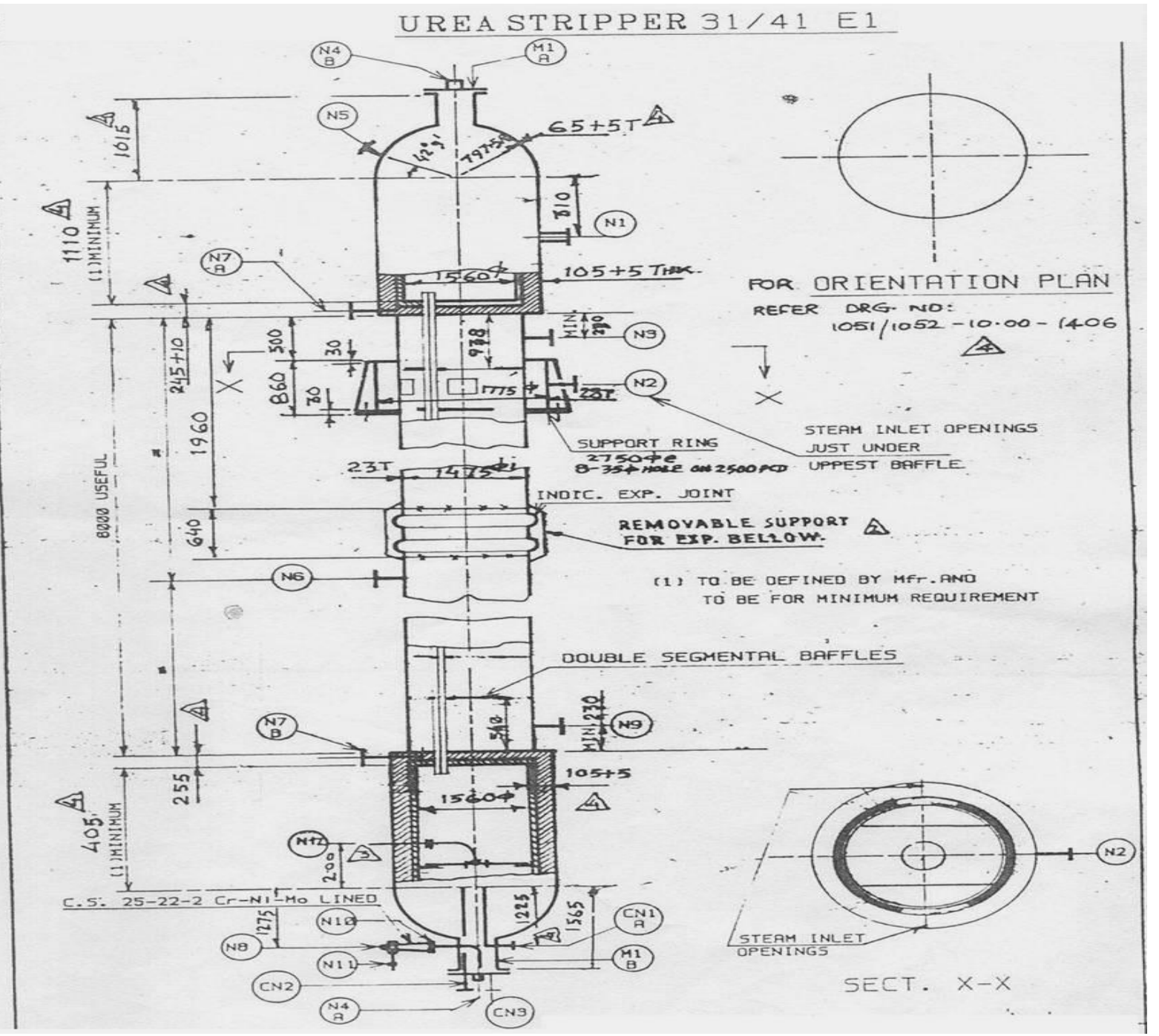

Fig-2

\begin{tabular}{|c|c|c|c|}
\hline Sr. No. & Parameters & Tube side & Shell side \\
\hline 1 & Pressure design & 165 bar & 26 bar \\
\hline 2 & Pressure working & 147 & 23 bar \\
\hline 3 & Temperature, $\quad$ In /Out & $190 / 205^{\circ} \mathrm{C}$ & $220 / 220^{\circ} \mathrm{C}$ \\
\hline 4 & Fluid & Urea Solution & Steam \\
\hline 5 & MOC & $\begin{array}{c}\text { Bimetallic outer-26/22/2, Inner - } \\
\text { Zirconium } \\
\end{array}$ & SA 516 GR 60 \\
\hline 6 & PSV set value & $165 \mathrm{bar}$ & 26 bar \\
\hline 7 & No. of pass & 1 & 1 \\
\hline 8 & No of tube & \multicolumn{2}{|c|}{1677} \\
\hline 9 & Heat transfer area & \multicolumn{2}{|c|}{$632.21 \mathrm{~m}^{2}$} \\
\hline 9 & Tube length & \multicolumn{2}{|c|}{$6000 \mathrm{~mm}$} \\
\hline 10 & Tube ID & \multicolumn{2}{|c|}{$20 \mathrm{~mm}$} \\
\hline 11 & Tube OD & \multicolumn{2}{|c|}{$22.7 \mathrm{~mm}$} \\
\hline 12 & Heat Duty & \multicolumn{2}{|c|}{$19.19 \times 10^{6} \mathrm{k} . \mathrm{cal} / \mathrm{hr}$} \\
\hline 13 & Pitch & \multicolumn{2}{|c|}{$25 \mathrm{~mm}$ triangular } \\
\hline
\end{tabular}

Table-1 


\section{STRIPPER \& V-29, STEAM \& CONDENSATE DISTRIBUTION}

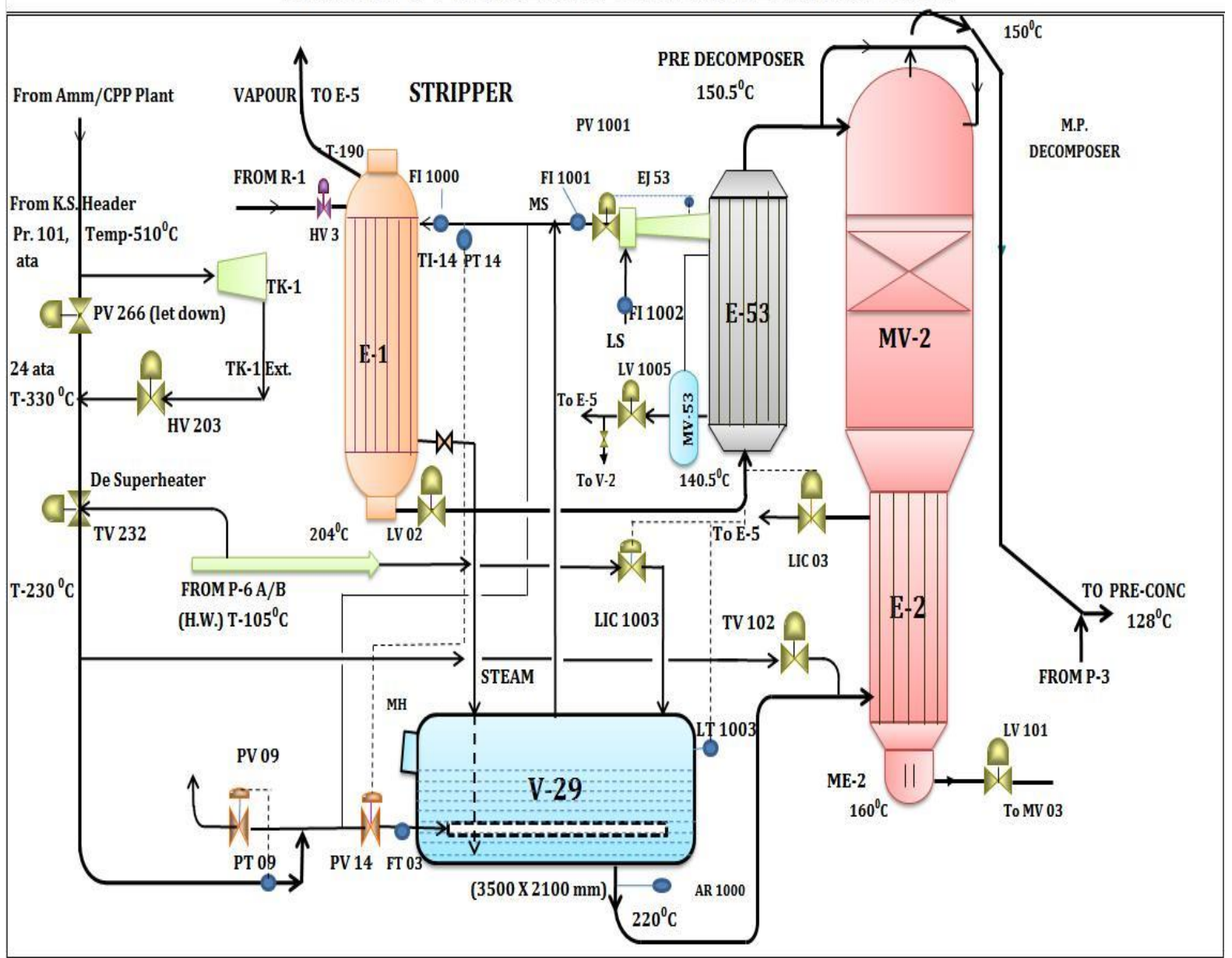

Fig-3

An ammonia rich gas $\left(\mathrm{CO}_{2}\right.$ lean gas) rises from lower parts of the tube, then the gas at the upper parts of the tube becomes an ammonia richer gas as compared with equilibrium composition and the decomposition reaction in liquid phase correct the deviation from the equilibrium (the stripping effect). Carbamate is decomposed at reactor pressure with the help of one of the reactants. First thing that comes into mind while going to look for leakage in such high pressure vessel is that, what are the potential points that can lead to leakage in such thick metal walls. There are three surfaces in contact with highly corrosive Carbamate solution.
1. Tube sheet.
2. Tube itself.
3. Tube to tube sheet joint.

The tube sheet thickness is $255 \mathrm{~mm}$ including $10 \mathrm{~mm}$ overlay as shown in the figure-2. The leakage develops when overlay eaten with corrosion/erosion, less passivation. The condensate outlet of stripper collects to steam condensate drum. The rest energy of this steam condensate uses in MP decomposer. In this line conductivity meter also installed for quick indication of leakage ranging $0-500 \mu$ mho. Also if there is any leakage in Stripper tubes or tube sheet, it shall be picked up in steam condensate leaving Stripper shell side. This will appear in the form of high conductivity. Monitoring of fresh steam entering into steam drum and condensate leaving the steam drum is very important and its delta (increase in conductivity of condensate leaving steam drum with respect to incoming steam) will determine the extent of leakage.

\section{REASON OF LEAKAGE}

The main reason of plug failure is old age of equipment i.e. 21 years old vessel. The old 55 numbers tube plugs failure one by one due to layers of welding gradually deteriorated. Corrosion and exposure of hidden defect in tube-to-tube sheet joint. Lack of passivation air. Leakage was so heavy that steam to stripper turned to zero immediately and stripper shell immediately pressurized up to PSV set value i.e. 26 bar, as shown in the figure- 4 
Job hand over

After plant stopped the job handed over to mechanical maintenance after 24 hrs. for top \& bottom manhole cover opening. The all activities plant shut down to plant start-up listed below-

\begin{tabular}{|c|c|c|c|c|c|c|}
\hline \multicolumn{7}{|c|}{31 Stream Shut Down Timing } \\
\hline $\mathrm{Sr}$ No & Astivitio & From & To & \multirow{3}{*}{ Total hrs } & Date & \multirow{3}{*}{ Parallel Activities } \\
\hline 年 & 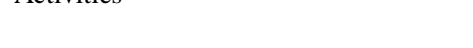 & Hrs & Hrs & & $\stackrel{\infty}{=}$ & \\
\hline 1 & Feed Cut & 5.30 & Hrs & & $\begin{array}{l}1 \\
\vdots \\
\vdots \\
0\end{array}$ & \\
\hline 2 & H.P. Loop Draining & 5.45 & 11.0 & 6.15 & $\begin{array}{l}\dot{1} \infty \\
\stackrel{1}{0} \\
\stackrel{2}{2}\end{array}$ & $\begin{array}{l}\text { Alternate Nut/Bolt Opening by } \\
\text { Mech. Maint, Nucleonic Opening }\end{array}$ \\
\hline 3 & LS Purging & 11.0 & 13.0 & 4.00 & \multirow{7}{*}{ 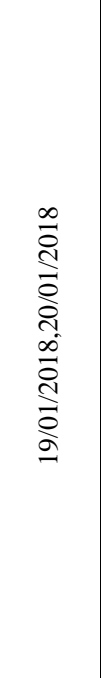 } & \\
\hline 4 & H.W Filling & 13.0 & 17.0 & 4.00 & & 31 Stream Steam Isolated \\
\hline 5 & HW Overflowing & 17.0 & 21.0 & 4.00 & & $\begin{array}{l}\text { Blind to be provided in } \mathrm{V}-29 \& \mathrm{E}- \\
1 \text { Inlet line. }\end{array}$ \\
\hline 6 & Draining only stripper & 21.0 & 22.0 & 1.00 & & Reactor/E-5 Draining \\
\hline 7 & $\begin{array}{l}\text { H/o To Mech Maint for Top/Bottom } \\
\text { man Hole cover opening }\end{array}$ & 22.0 & 4.00 & 6 & & \\
\hline 8 & Cooling By Air/DM water & 4.00 & 10.0 & 6.00 & & MP loop draining \\
\hline 9 & Sample analysis for $\mathrm{O}_{2} /$ Ammonia & 10.00 & 10.15 & 0.25 & & 31 LT 101 job \\
\hline 10 & $\begin{array}{l}\text { Man entry for top/Bottom internal } \\
\text { opening }\end{array}$ & 10.15 & 16.00 & 6.00 & \multirow{2}{*}{ 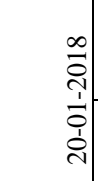 } & \\
\hline 11 & Leakage detection & 16.00 & 17.00 & 1.00 & & Others job \\
\hline 12 & Job by Mech Maint for leakage/welding & 17.00 & 0.00 & 7.00 & \multirow{7}{*}{ 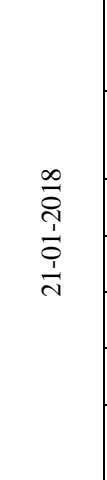 } & \\
\hline 13 & Leakage checked after Job Over & 0.00 & 1.00 & 1.00 & & \\
\hline 14 & DP test & 1.00 & 3.00 & 2.00 & & \\
\hline 15 & Stripper internal boxed up & 3.00 & 9.00 & 6.00 & & Blinds removed \\
\hline 16 & Manhole cover boxed up & 9.00 & 15.00 & 6.00 & & Steam Charging \\
\hline 17 & L.S Heating & 15.00 & 19.00 & 4.00 & & \\
\hline 18 & K.W. Heating & 19.00 & 22.45 & 3.75 & & $\mathrm{CO}_{2}$ Compressor running \\
\hline 19 & Ammoniation & 22.45 & 3.00 & 4.00 & \multirow{2}{*}{ 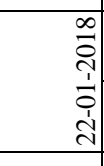 } & \\
\hline 20 & Feed In & 3.00 & & & & \\
\hline & Total hrs & & & 72.15 & & \\
\hline
\end{tabular}

Table-2 


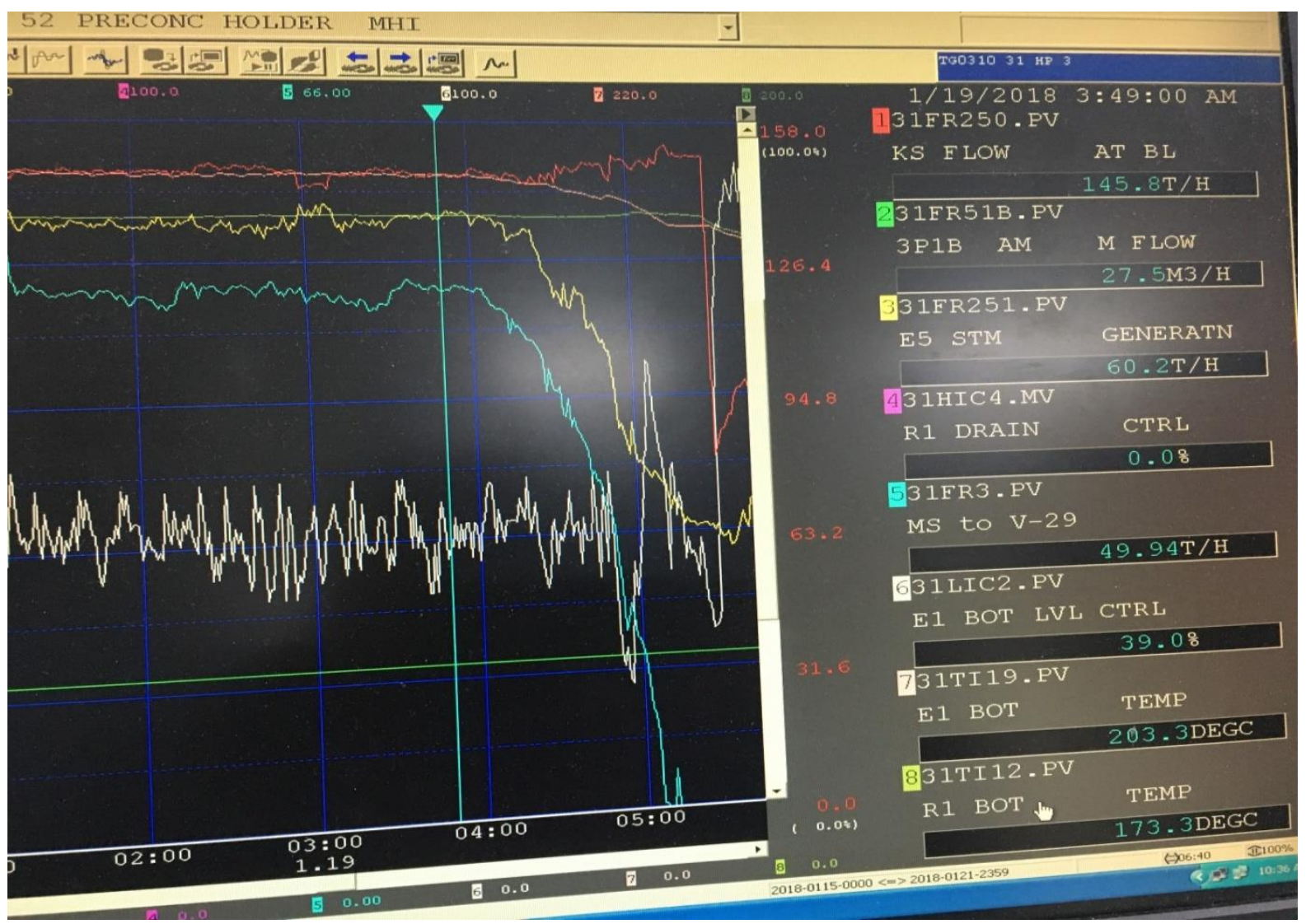

\section{STEAM REDUCED TO ZERO AFTER LEAKAGE}

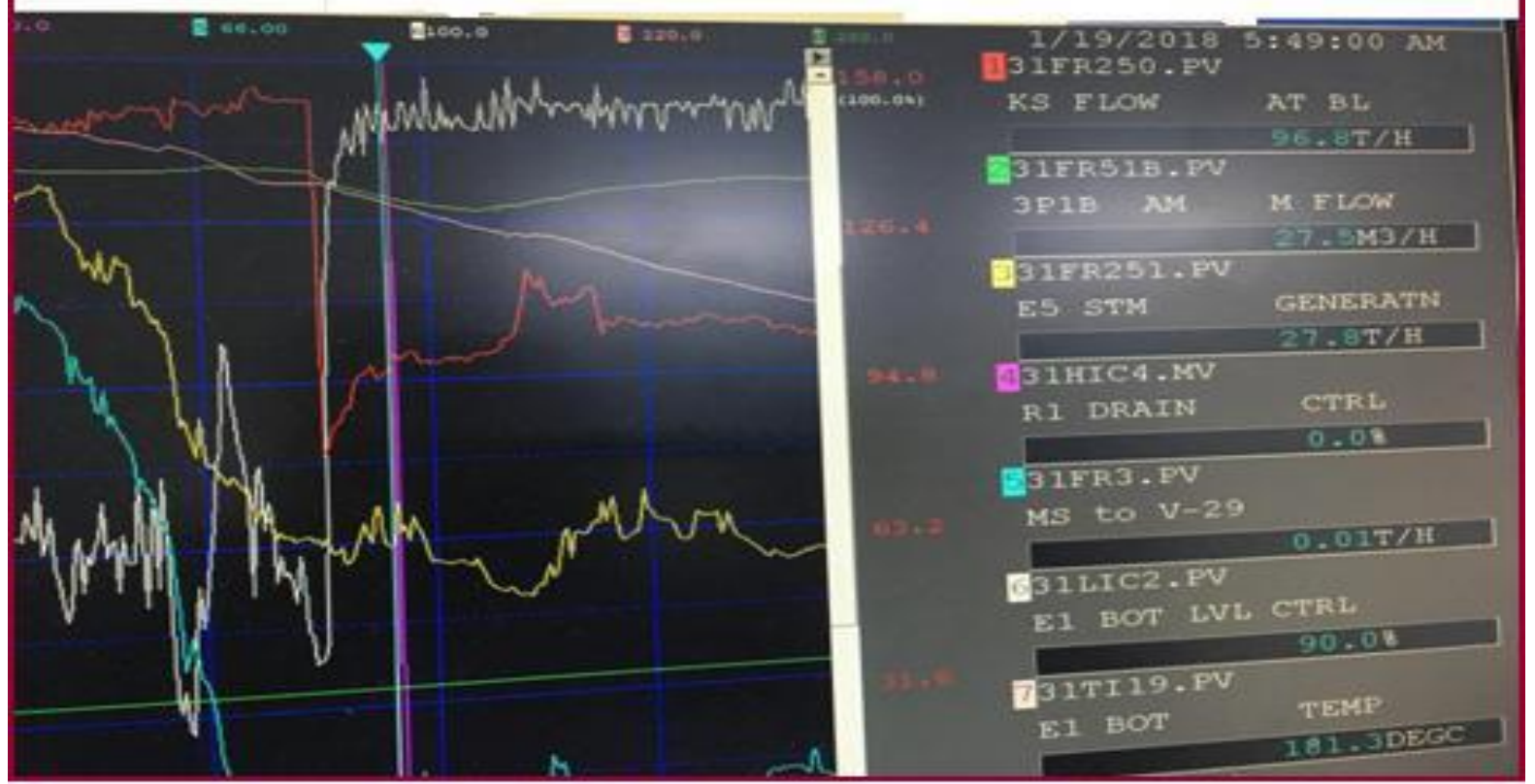

Fig-4

\section{Detection of the leakage}

Arrangement as shown in the figure- 7 was done for getting tube leakage detection. Blind are provided to following equipment lines.

1. Steam to shell side inlet line

2. Outlet line i.e. V-29 vessel
The Shell side pressurized with instrument air at the pressure 7.0 bar and leakage detects with soap solution in top \& bottom dome(Channel). Air \& soap solution test is the most effective and safe for detection of leakage. Although it is the time consuming test and finding the defects but increasing the inspectors during the test serves the purpose. The test was carried out by pressurizing the shell side with 
air at 6.5-7.0 bar. After pressurization, inspectors can readily enter into both the channel sides with soap solution and can start finding the leaking points. It requires much of attention and skill of inspector to look for all the defects. Full scanning is must and a cumbersome job. The salient features of this test are:

1. Reliable and effective but time consuming.

2. Good for all small and large leakages.

3. Safe and less risky than ammonia leak test.
After the confirmation of leakage in both the channel it's the responsibility of Inspection and welding by expert welder to arrest the leakage in Urea Stripper. Major culprit plug leakage detects easily without applying soap solution air was coming from the damaged plug. For further minor leakage detection, a team was deputed for top \& bottom channel. Following minor leakages were also detected as shown in the figure- 8 .
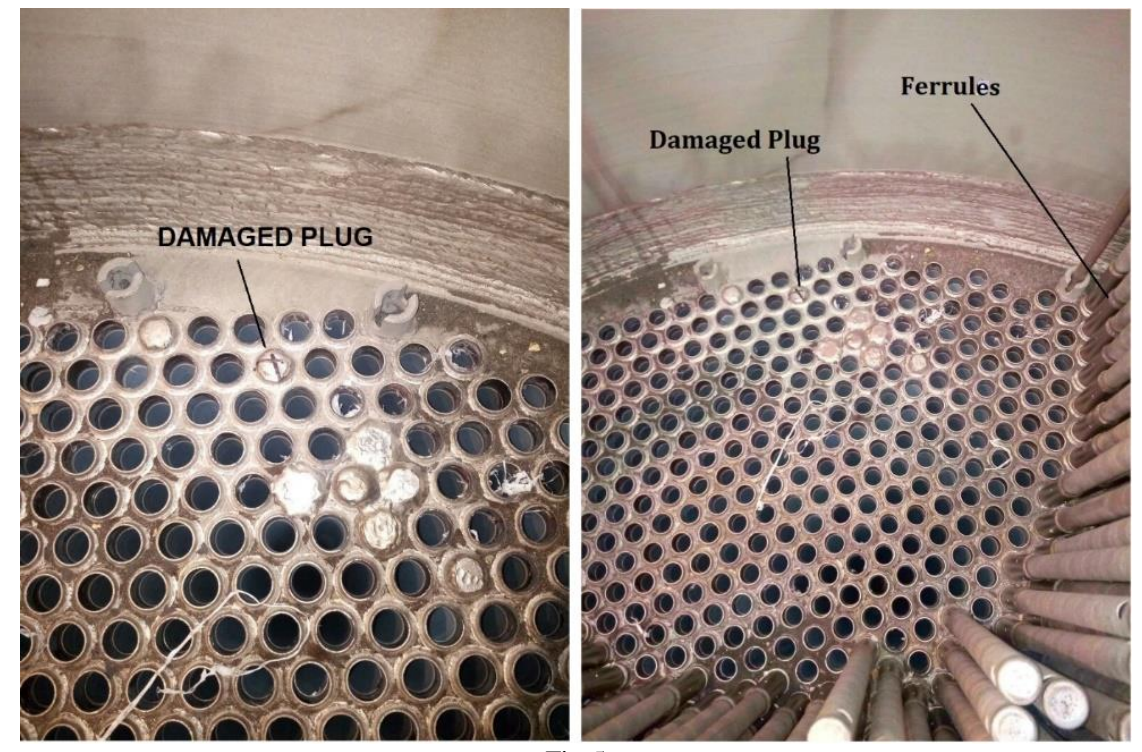

Fig-5

Old plug removing is very risky

When old plug removing the tubes filled with ammonium carbamate \& urea solution. So the B.A set and protection apparatus are used to remove the old plugs. Preparation and Installation work can be done by experts of fitting \& welding persons. In case of a leak one can easily check if there is any damage of tube sheet as corrosion would start from the inside the tube sheet hole. Replacing a new plug with 2 RE-69(25/22/2) takes max 15 minutes and can be done with a protection mask when ammonia is present.

\section{Rectification of defects}

The rectification of defects was carried out very carefully as it involves welding adjacent to the healthy tubes and tubeto-tube sheet joints. Following guidelines was follow listed below:
1. Grinding was done effectively in order to flush the pin hole completely. Ineffective grinding would never rectify the leaking point.

2. Welding was made after dye-penetrate testing of ground off area.

3. TIG welding with lower heat input was used for rectification.

4. Adjacent tubes and tube sheet weld joints avoided. Certain jigs used for the same in order to concentrate the welding heat where required.

5. Qualification of welder was made before welding in this sensitive area. High heat input will cause burn thru / HAZ area which would eventually be a potential point of leakage.

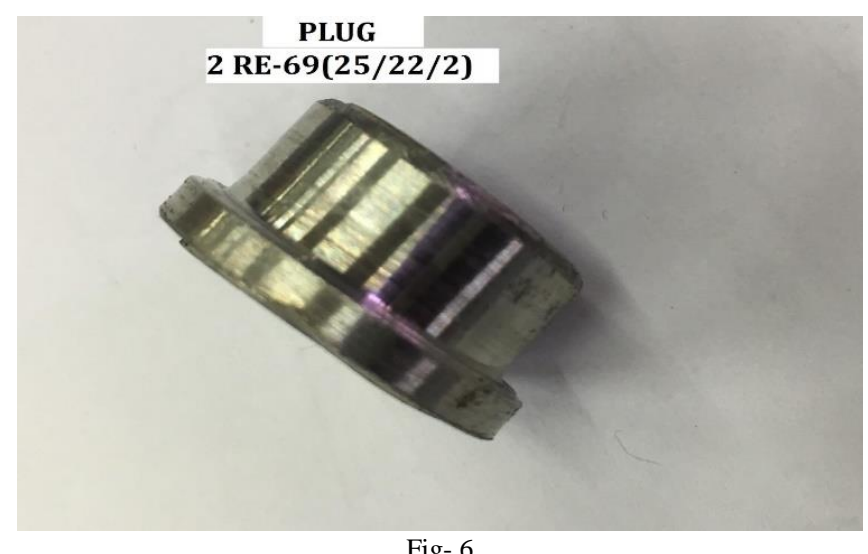

Fig- 6 
The 2 RE 69 (25/22/2) material plugs were applied on defected tubes. Each and every time leakage was detected with DPT and air/soap solution.

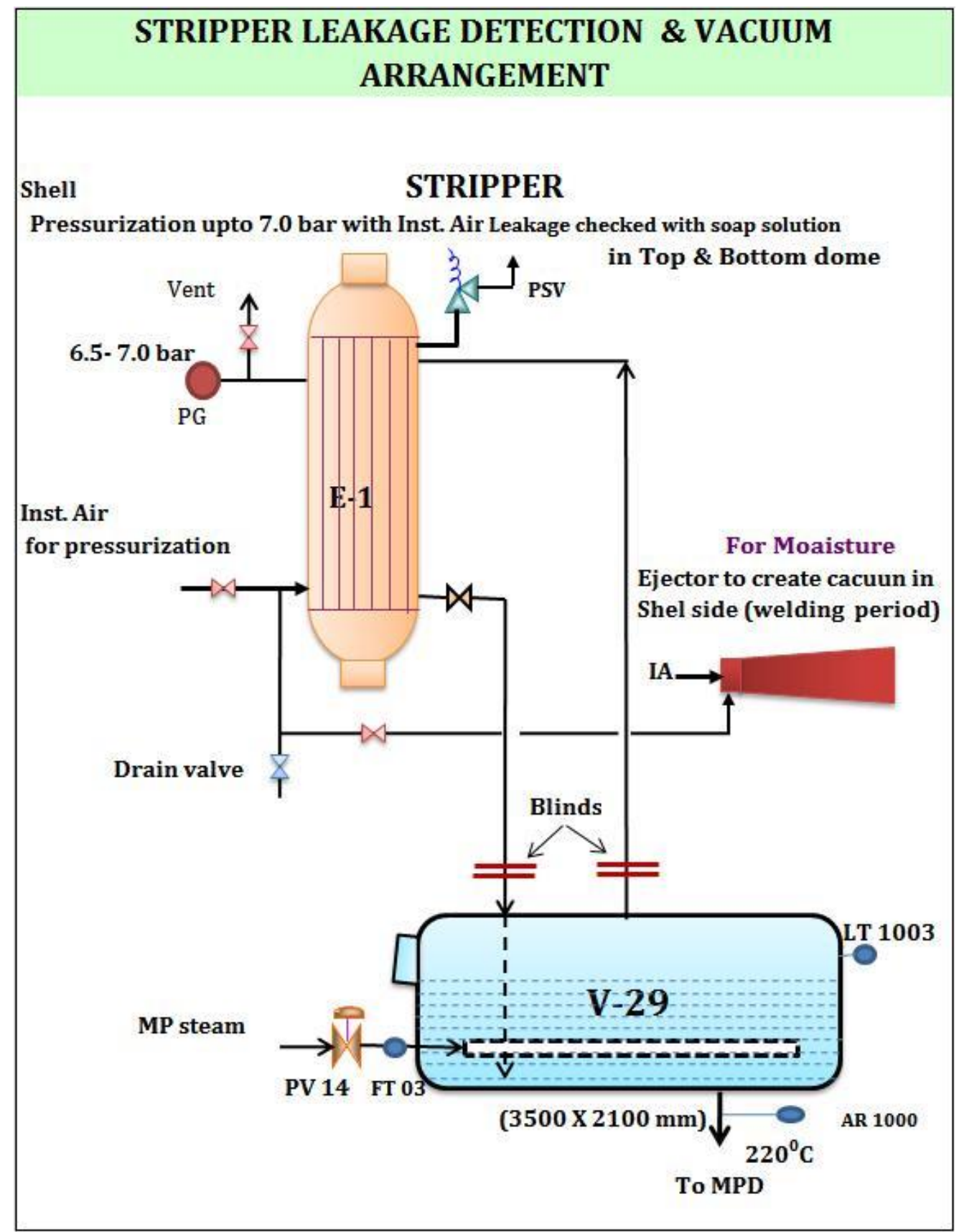

Fig-7

1. Replaced three old plugs at top channel.

2. Two number in bottom channel.

3. Two number new tubes plug at top \& bottom. 


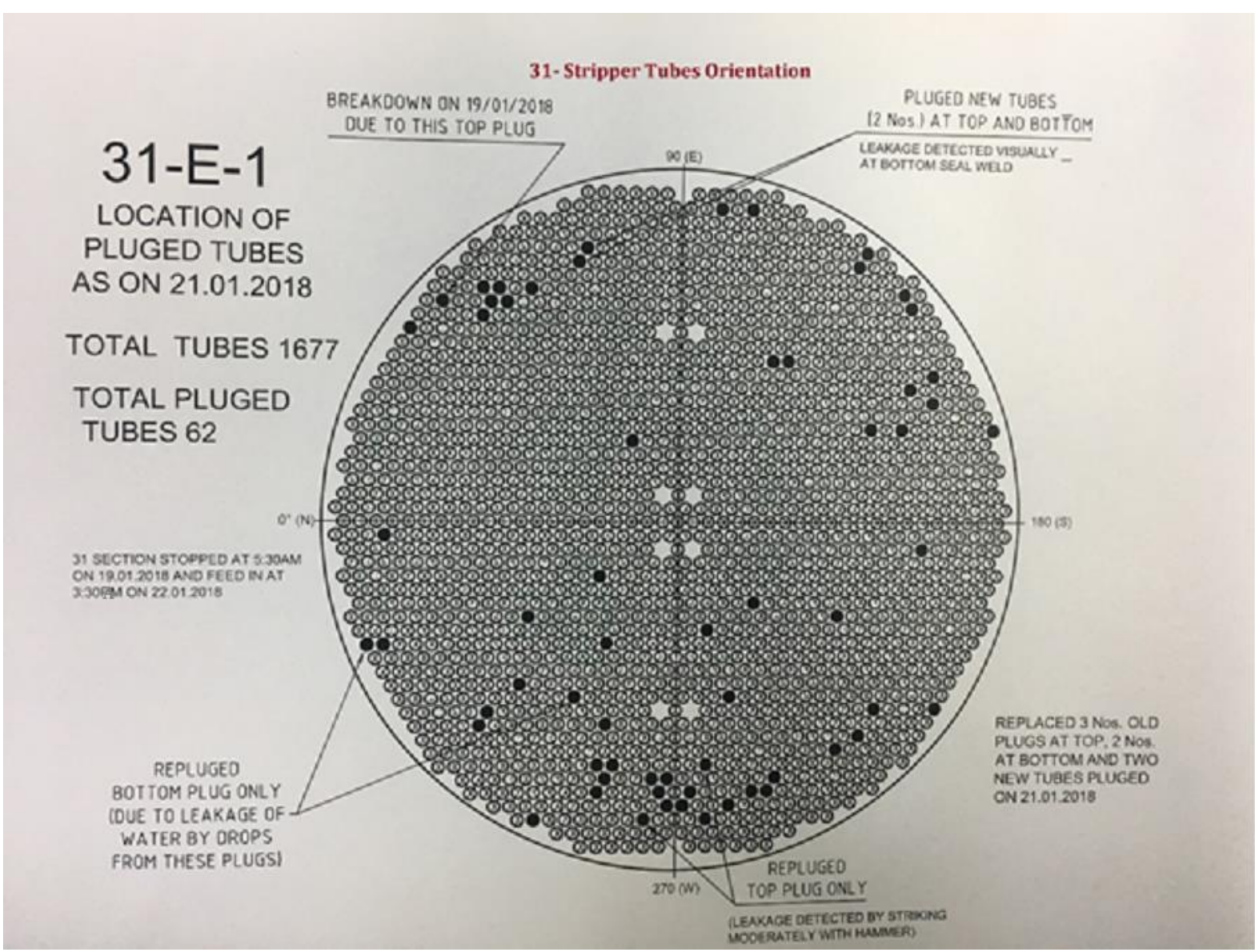

Fig-8

\section{CONCLUSION}

When stripper problems occur, they take at least 3-4 days to fix the problems. The large nature of strippers means spare parts are not available onsite and could take weeks to be installed. Even minor leaks mean shutting down the stripper, cooling it, washing out its interior and starting it back up. Just shut-down and start-up procedures could take days. The result is often money of lost revenue. If a stripper experiences accelerated corrosion that causes the wall thickness to fall below required safety margins, the result could be dangerous. The observation and inspection results indicate that active corrosion in the top part of tubes however the passivation air is sufficient in top part of the channel. Physical condition of replaced original plugs indicates severe erosion/Corrosion. Difficult weld position risk for damaging surrounding tube ends very high risk for porosities \& worm holes due to moisture, to avoid moisture coming down during welding at bottom tube sheet an ejector system was installed in shell side to remove moisture. Repeated heat input a leaking plug weld is the main cause for an unexpected plant shut down when looking at HP heat exchanger failure modes replacing a welded plug requires minimum 11 hours. Omega Bond Tubing is the next generation solution; it is the only technology that combines the benefits of zirconium and titanium, ideally optimizing urea processing. In omega bond no need of passivation air.

\section{LEGENDS}

TPD-ton per day, H.P-high Pressure, M.P. medium pressure, MW-megawatt. MOC- material of construction, 2-RE-69(25/22/2-Chromium. Nickel \& molybdenum), L.S-low pressure steam(4bar), H.W. High pressure water (35 bar), K.W.-very high pressure water (160 Bar), B.A. set-breathing apparatus set. 